\begin{abstract}
А.А. Казаков
Барнаульский юридический институт МВД России ул. Чкалова, 49, Барнаул, 656038

E-mail: kaa-2862@mail.ru

\section{КЕРАМИЧЕСКИЙ КОМПЛЕКС МАЙМИНСКОЙ АРХЕОЛОГИЧЕСКОЙ КУЛЬТУРЫ}

Работа посвящена анализу керамического комплекса майминской археологической культуры, ранее не предпринимавшемуся ни одним из исследователей, с целью выявления этапов и эволюционной линии развития культуры. На основании качественного и количественного анализа по пяти основаниям (фрорма сосуда, форма дна, форма венчика, орнаментальный элемент, орнаментальный мотив) выделены три группы памятников, которые соотносятся с тремя этапами ее развития. Построена относительная хронология этапов развития культуры, намечены их абсолютные хронологические рамки. Этапы получили название по наиболее характерным памятникам - сайлапский, горноелбанский и новозыковский. Предложена схема формирования культуры, появившейся в исследуемом регионе (среднее течение Бии - нижнее течение Катуни) в результате миграции инокультурного населения, намечена эволюционная линия развития керамического комплекса и представлена гипотеза относительно дальнейшей исторической судьбы культуры.
\end{abstract}

Ключевые слова: керамика, морфология, орнамент, археологическая культура, этап, эволюция, анализ.

DOI: $10.20874 / 2071-0437-2018-43-4-074-083$

Светлой памяти М.Т. Абдулганеева

Майминская археологическая культура была выделена (как майминский тип керамики) и кратко охарактеризована М.Т. Абдулганеевым в начале 1990-х гг. [1992, 1993], однако до сих пор остается «вещью в себе». В настоящее время накоплена достаточная источниковая база, позволяющая структурировать материалы культуры, выделить этапы и, таким образом, наметить эволюционную линию ее развития.

По опубликованным источникам насчитывается 29 памятников майминской культуры (рис. 1). Из них 18 расположены в Алтайском крае, 11 - в Республике Алтай. Все памятники майминской культуры представляют собой поселенческие комплексы, известен лишь один погребально-поминальный комплекс в полу жилища на поселении Ушлеп 5, но его культурно-хронологическая принадлежность к майминской культуре дискуссионна [Кунгуров, Горбунов, 1993]. Так как самым информативным материалом с поселений является керамика, в качестве объекта изучения выбран керамический комплекс.

При анализе керамического материала использовались проверенные методики, апробированные Л.А. Чиндиной [1984, 1991], Т.Н. Троицкой [1979] и автором [Казаков, 2014].

Для проверки полученных результатов дополнительно был проведен многомерный статистический анализ, а именно кластер-анализ по методу полных связей (complete linkage method) с использованием алгоритма «дальнего соседа», когда основанием для присоединения каждого следующего объекта к тому или иному кластеру является его близость к наименее похожему на него объекту этого кластера [Абдулганеев, Владимиров, 1997, с. 50]. Обрабатывался материал по уже апробированной методике подсчета степени близости всех объектов исследуемых совокупностей посредством расчета коэффрициента общего сходства Гауэра [Матренин, Тишкин, 2007 , с. 107] с последующим преобразованием этих коэффициентов в кластеры [Григоров, Казаков, 2018] (выражаю искреннюю благодарность И.А. Казакову за проведенные расчеты и подготовку дендрограмм).

Ввиду немногочисленности выборок материала при его обработке учитывалось только наличие того или иного признака, без его статистической распространенности внутри керамического комплекса. Поэтому матрицы составлялись по принципу бинарной оппозиции «да - нет».

Коллекции, которые имеют минимальный набор признаков для первичного качественного и количественного анализа, происходят с 10 памятников, расположенных по всему ареалу май- 
минской археологической культуры. Это городища Сайлап, Курлап (Курлак) [Скопинцева, 1993], Черемшанка, Манжерокское (Манжерок 3) [Соенов и др., 2016, с. 47-77], Усть-Иша За [Абдулганеев и др., 2001, с. 93; Абдулганеев, 2007, с. 258] и поселения Новозыково 3 [Казаков, Демин, 1992], Ушлеп 5 [Кунгуров, Горбунов, 1993, с. 99; Абдулганеев и др., 1995], Сайлапский Взвоз [Казаков, 1995], Горный Елбан [Абдулганеев и др., 2005] и Майма 1 [Абдулганеев, 1998, с. 166].

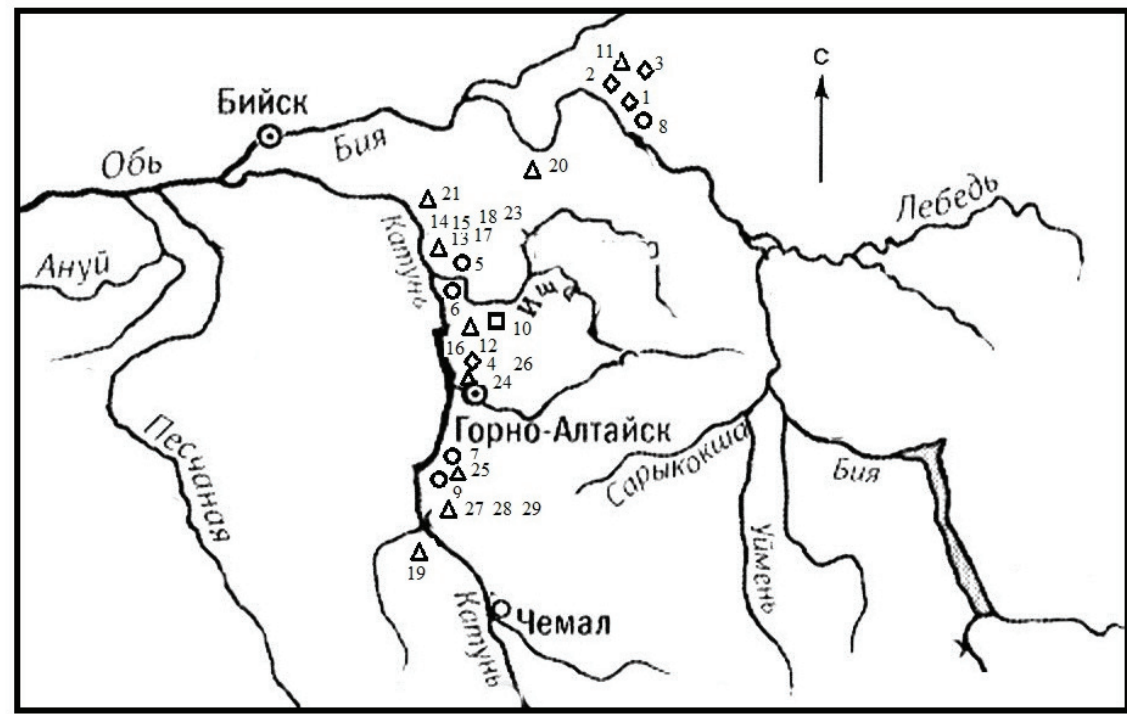

\footnotetext{
• - памятники сайлапского этапа (site of Sailap stage).

○ - памятники горноелбанского этапа (sites of Gornyi-Elban stage).

口 - памятники новозыковского этапа (sites of Novozykovo stage).

$\Delta$ - памятники майминской культуры безотносительно к этапам (sites of Maima culture without stage belonging).
}

Рис. 1. Расположение памятников майминской культуры:

1 - Сайлап; 2 - Курлап; 3 - Ушлеп 5; 4 - Майма 1; 5 - Горный Елбан; 6 - Усть-Иша 3а; 7 - Черемшанка; 8 - Сайлапский Взвоз; 9 - Манжерокское; 10 - Новозыково 3; 11 - Курлап 2; 12 - Усть-Иша 3б; 13 - Новосуртайка; 14 - Маяк 1; 15 - Верх-Иша 1; 16 - Верх-Иша 3; 17 - Горный 9; 18 - Горный 12; 19 - Емурлинское; 20 - Солонцы;

21 - Березовка 2; 22 - Техникум; 23 - Долина Свободы 2; 24 - Майма 14; 25 - Чултуков Лог 9; 26 - Майма 7; 27 - Барангол 5; 28 - Нижний Чепош 3; 29 - Нижний Чепош 4.

Fig. 1. Map of Mayma culture sites:

1 - Sailap; 2 - Kurlap; 3 - Ushlep 5; 4 - Mayma 1; 5 - Gornyi Elban; 6 - Ust'-Isha 3a; 7 - Cheremshanka; 8 - Sailapskii Vzvoz; 9 - Manzherokskoe; 10 - Novozykovo 3; 11 - Kurlap 2; 12 - Ust'-Isha 36; 13 - Novosurtaika; 14 - Mayak 1; 15 - Verkh-Isha 1; 16 - Verkh-Isha 3; 17 - Gornyi 9; 18 - Gornyi 12; 19 - Emurlinskoe; 20 - Solontsy; 21 - Berezovka 2; 22 - Tekhnikum; 23 - Dolina Svobody 2; 24 - Mayma 14; 25 - Chultukov Log 9; 26 - Mayma 7; 27 - Barangol 5; 28 - Nizhnii Cheposh 3; 29 - Nizhnii Cheposh 4.

Анализу подверглись как морфологические особенности керамического комплекса (форма сосудов, фрорма дна, фрорма венчиков), так и особенности орнаментации (орнаментальный элемент, орнаментальный мотив). В результате получилось пять таблиц, на основании которых составлена исходная матрица, включающая все характеристики керамического комплекса майминской культуры. Первичный анализ по формам позволил выделить четыре группы памятников.

На памятниках первой группы преобладают горшковидные формы с развитой шейкой и экватором выше центра тулова. К этой группе относятся Горный Елбан, Усть-Иша За, Майма 1 и Черемшанка.

Ко второй группе памятников относится поселение Новозыково 3, только на нем встречены горшки несколько иных пропорций (шаровидное тулово - экватор проходит примерно посередине тулова) и горшки с прямым устьем. На этом памятнике не отмечено ни одной из наиболее распространенных форм - горшков с развитой шейкой и экватором выше центра тулова.

К третьей группе можно отнести городище Курлап. Только на этом памятнике встречены кубковидные сосуды. К четвертой группе относится поселение Ушлеп 5, занимающее промежуточное положение между городищем Курлап, на котором, как и на поселении Ушлеп 5, присутствуют пиалы 


\section{А.А. Казаков}

с плоским дном, и основной группой памятников с горшковидными сосудами с развитой шейкой и экватором выше центра тулова. Формализованный анализ подтверждает полученные выводы.

Сильная фррагментация сосудов из керамических комплексов поселений не всегда позволяет реконструировать фрормы, поэтому приходится анализировать еще и отдельные элементы форм, такие как днища и венчики.

По фрорме дна также выделяется несколько групп памятников. К первой относятся Новозыково 3, Майма 1, Манжерок 3, Черемшанка и Усть-Иша За. На этих памятниках встречены только плоские днища и плоские днища с намечающимся поддоном. Вторую группу составляют комплексы с поливариантными фрормами днищ - плоскими и круглыми. Это памятники Сайлап, Курлап, Ушлеп 5. К третьей группе относятся комплексы с днищами на поддонах: Курлап, Ушлеп 5 и Горный Елбан. Поселения Ушлеп 5 и Курлап входят как во вторую, так и в третью группу памятников, т.е. занимают своеобразное, промежуточное положение.

Важным морфологическим признаком является фрорма венчика сосуда. Основываясь на совпадениях и их отсутствии, можно выделить следующие группы памятников. К первой относятся городища Курлап и Сайлап, к ней примыкают (по три совпадения) Манжерок 3, Майма 1, Ушлеп 5. Ко второй - Усть-Иша За, Горный Елбан, Черемшанка, Ушлеп 5, Сайлапский Взвоз. К третьей группе, на основании близости к хорошо выделяемому поселению Новозыково 3, относятся Курлап, Ушлеп 5, Майма 1, Сайлапский Взвоз. Наиболее универсальным, совмещающим в себе признаки всех трех выделенных групп, является Ушлеп 5. Сайлапский Взвоз занимает промежуточное положение между второй и третьей группами памятников. Полученные выводы подтверждаются дендрограммой, построенной по данным о форме венчика.

Анализ по элементам орнамента показал, что наиболее распространенными в орнаментальной композиции, встреченными практически на всех памятниках майминской культуры, являются такие элементы, как ямки, гладкий штамп и пальцевые (ногтевые, защипные) элементы. На керамике семи памятников из десяти, что также говорит о широком распространении, встречены насечки. В орнаментации сосудов шести памятников отмечается крупнозубый гребенчатый штамп. В трех комплексах встречены S-образный гладкий штамп (уточка), полулунный штамп, наколы неправильной формы. Редкими, отмеченными на посуде двух памятников, являются гладкий штамп с усиленным концом и широкий гладкий штамп с усиленным концом. В одном комплексе зафиксированы каннелюра и отпечаток уголка лопаточки.

Основываясь на совпадениях орнаментальных элементов или на их отсутствии, можно выделить следующие группы памятников.

К первой относятся Сайлап, Курлап, Ушлеп 5, Майма 1.

Ко второй - Сайлапский Взвоз, Горный Елбан, Усть-Иша За, Черемшанка, Манжерок 3 и Курлап.

К третьей - поселение Новозыково 3, Курлап, Сайлапский Взвоз.

Можно выделить памятники, занимающие промежуточное положение между группами или входящие как в одну, так и в другую группу. Наиболее универсальным, вошедшим во все три группы, является Курлап. Сайлапский Взвоз занимает промежуточное положение между второй и третьей группами, являясь связующим звеном между ними.

Полученные выводы хорошо согласуются с дендрограммой.

Анализ орнаментальных мотивов показал, что на керамике всех памятников майминской культуры имеется горизонтальный мотив. Вертикальный отмечен в 8 из 10 комплексов, наклонный и комбинированный - в 7, елочка - в 5, зигзаг - в 4. Редкими, встреченными на посуде одного памятника, являются фестон и ленточный мотив.

Наибольшее разнообразие мотивов наблюдаем в комплексах поселений Майма 1 (7 из 8), Новозыково 3 (6 из 8) и Ушлеп 5 (5 из 8).

Дальнейший анализ по принципу количества - отсутствия совпадений не позволил выделить каких-либо закономерностей, позволяющих объединить памятники в группы.

На построенной по этому признаку дендрограмме выделяются следующие группы памятников: первая - Черемшанка, Манжерок 3; вторая - Новозыково 3, Майма 1, Сайлапский Взвоз, Сайлап, Курлап. Ушлеп 5 занимает промежуточное положение между этими группами. Насколько объективны данные дендрограммы при столь незначительном количестве исходных, судить трудно.

Проведем корреляцию данных, полученных по различным основаниям.

Наиболее специфичными, отличающимися друг от друга по большинству оснований, являются такие памятники, как Сайлап, Горный Елбан и Новозыково 3. Эти памятники ни разу не 
встречаются в одной группе при делении по разным основаниям, следовательно, между ними самые большие различия. Поэтому именно эти памятники образуют ядра групп, вокруг которых будут формироваться схожие типы керамики.

В одной группе вместе с Сайлапом при классификации по разным основаниям в трех случаях встречены Курлап, Ушлеп 5, в двух случаях - Майма 1. Учитывая наибольшее сходство между этими памятниками, будем считать их входящими в первую группу памятников.

В одной группе вместе с Горным Елбаном при классификации по разным основаниям встречены Усть-Иша За (3 раза), Черемшанка (3 раза), Курлап (2 раза), Ушлеп 5 (2 раза), Сайлапский Взвоз (2 раза), Манжерок 3 (1 раз), Майма 1 (1 раз). По наибольшему сходству в эту группу входят Горный Елбан, Усть-Иша За, Черемшанка, Сайлапский Взвоз, Манжерок 3.

Учитывая, что Курлап, Ушлеп 5 и Майма 1 по наибольшему количеству совпадений включены в первую группу, считаем, что они являются теми базисными, переходными комплексами, на основе которых фрормируются признаки керамического комплекса памятников второй группы.
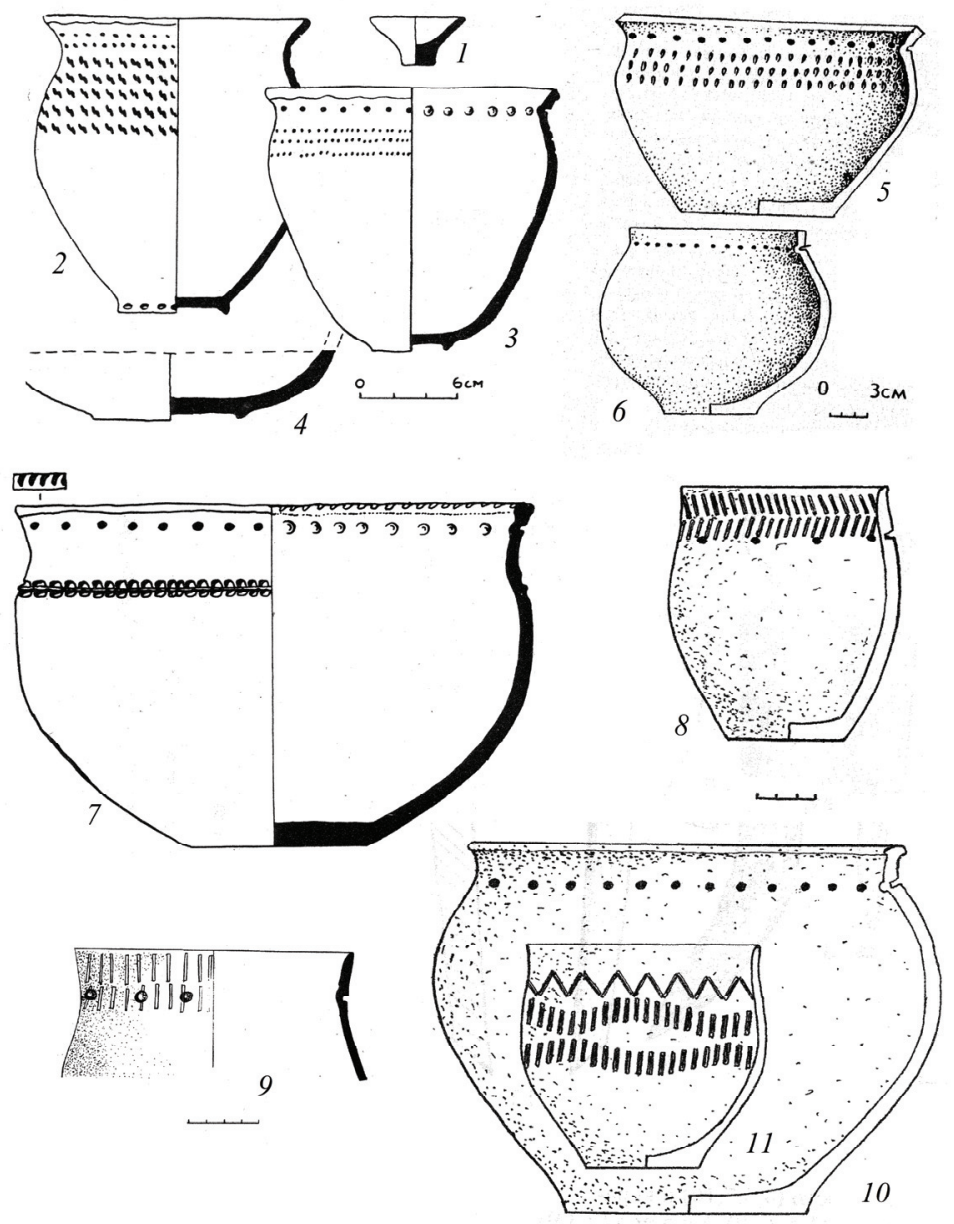

Рис. 2. Керамический комплекс сайлапского этапа (1-4, 7-Ушлеп 5 (по: [Кунгуров, Горбунов, 1993; Абдулганеев и др., 1995]); 8, 10, 11 - Майма 1 (по: [Абдулганеев, 1998]); 9 - Сайлап (по: [Скопинцева, 1993]). Fig. 2. Ceramic complex of Sailap stage (1-4, 7 - Ushlep 5 (according to: [Kungurov, Gorbunov, 1993; Abdulganeev et al., 1995]); 8, 10, 11 - Mayma 1 (according to: [Abdulganeev, 1998]); 9 - Sailap (according to: [Skopintseva, 1993]).

В одной группе вместе с Новозыково 3 встречены Майма 1 (2 раза), Курлап (2 раза), Сайлапский Взвоз (2 раза), Манжерок 3 (1 раз), Черемшанка (1 раз), Усть-Иша За (1 раз), Ушлеп 5 (1 раз). Учитывая, что все эти памятники по признакам большего сходства включены в другие группы, можно говорить о них как о базисных, переходных комплексах, на основе которых фрормируются основные признаки керамического комплекса памятников третьей группы, в настоящее время представленной единственным памятником - Новозыково 3. 


\section{А.А. Казаков}

Таким образом, анализ керамических комплексов с 10 памятников майминской археологической культуры позволил выделить три группы памятников, каждой из которых соответствует определенный тип керамики. Эти группы предлагается назвать по памятникам, имеющим наиболее выраженную идентичность,-— сайлапская, горноелбанская и новозыковская.

В сайлапскую группу входят Сайлап, Курлап, Ушлеп 5, Майма 1 (рис. 2).

В горноелбанскую группу входят Горный Елбан, Усть-Иша За, Черемшанка, Сайлапский Взвоз, Манжерок 3 (рис. 3).

В новозыковскую группу входит Новозыково 3 (рис. 4).

Считаем, что деление керамического комплекса майминской культуры на различные типы соответствует существованию определенных этапов в эволюции керамического комплекса в целом и имеет хронологическую природу. Предлагаем выделить в развитии майминской культуры этапы, а их названия соотнести с названиями выделенных групп памятников.

Принимая во внимание даты для некоторых памятников, таких как Майма 1, который М.Т. Абдулганеев относил к I в. до н.э. - IV в. н.э. [1993, с. 3], Ушлеп 5, отнесенный А.Л. Кунгуровым и В.В. Горбуновым к первой половине I тыс. н.э. [1993, с. 101], Новозыково 3, датированный автором VI-VIII вв., полагаем, что первым этапом майминской культуры является сайлапский, начинающийся с I в. до н.э., за ним следует горноелбанский, верхняя хронологическая граница которого - VI в., и заключительный - новозыковский, соответственно VI-VIII ВB. Вопрос о хронологической границе между сайлапским и горноелбанским этапом пока остается открытым; вполне возможно, она находится в пределах IV в.

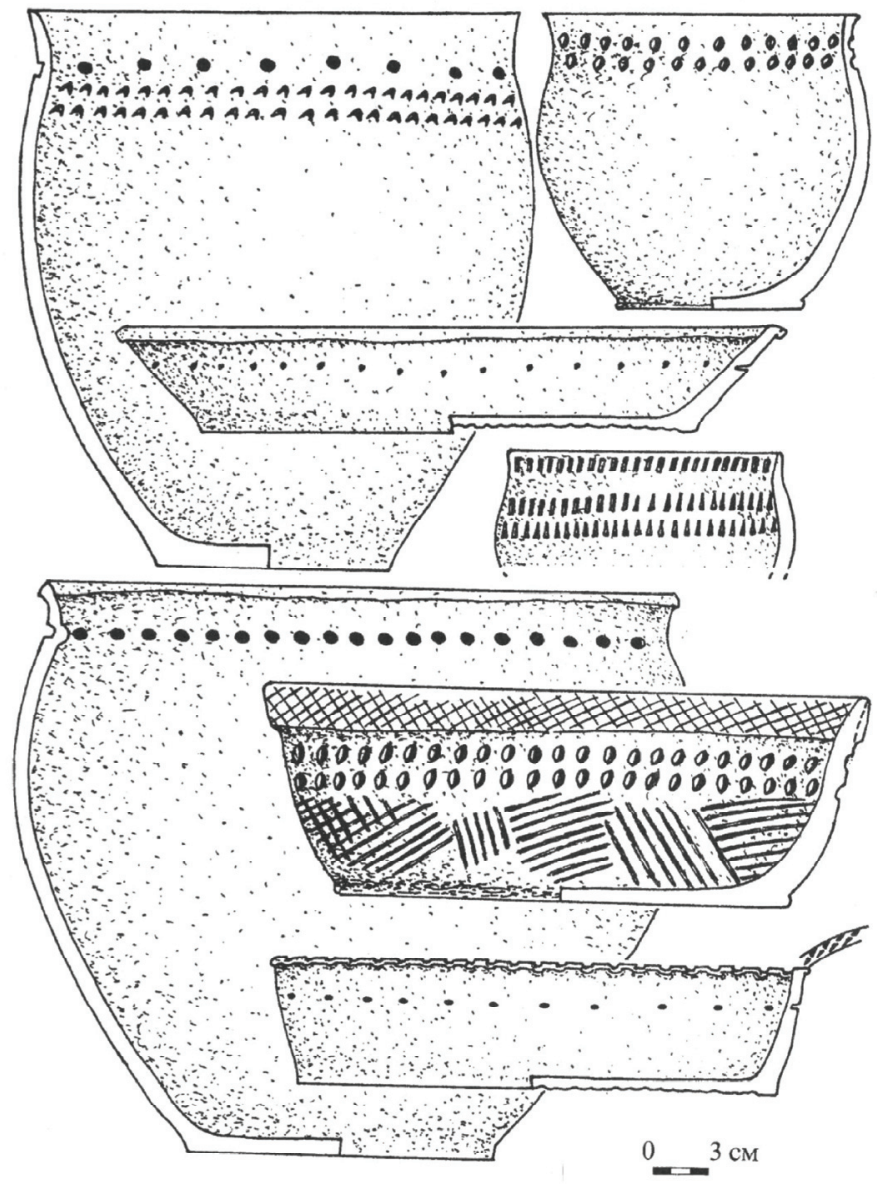

Рис. 3. Керамический комплекс горноелбанского этапа (Горный Елбан - по: [Абдулганеев и др., 2005]).

Fig. 3. Ceramic complex of Gornyi-Elban stage (Gornyi Elban - according to: [Abdulganeev and others, 2005]).

Учитывая выявленную относительно-абсолютную хронологию этапов майминской археологической культуры, на основании анализа ее керамического комплекса дадим его описание и попытаемся наметить закономерности развития. 

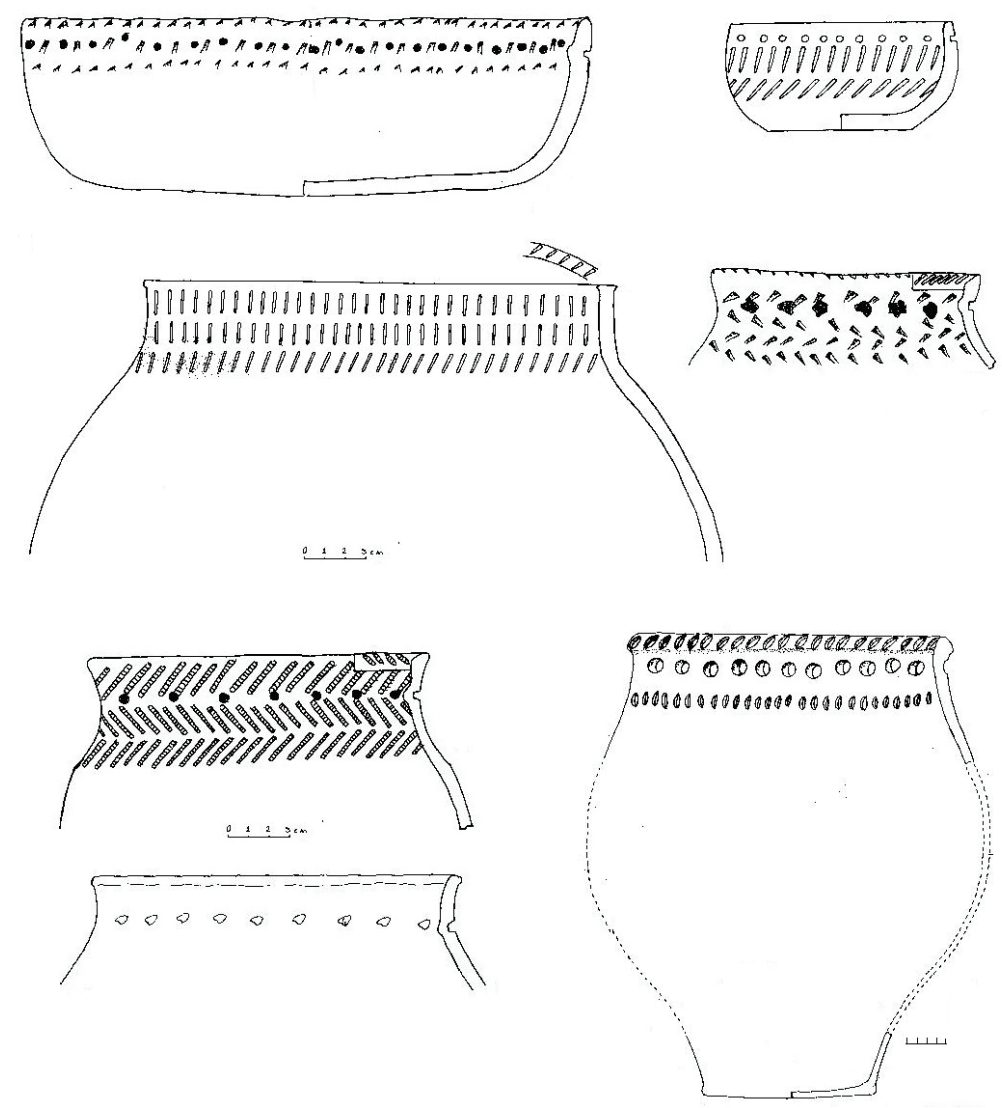

Рис. 4. Керамический комплекс новозыковского этапа (Новозыково 3).

Fig. 4. Ceramic complex of Novozykovo stage.

Наиболее полное его описание мы находим в работах М.Т. Абдулганеева, который характеризует его как плоскодонный, с преобладанием горшковидных сосудов, украшенных наколами различной формы. Отличительной особенностью майминской керамики М.Т. Абдулганеев считает широкое распространение гладкого штампа и крайне редкое использование гребенчатого [1992, с. 53; 1993, c. 4].

Полностью соглашаясь с приведенной характеристикой М.Т. Абдулганеева, дополним ее. Формы сосудов майминской культуры значительно более разнообразны. Многие комплексы имеют посуду с различными формами дна - наряду с плоскодонными представлены сосуды с различными вариантами круглодонности и на поддонах. Сосуды на поддонах не характерны для керамических комплексов предгорного, лесостепного и горного Алтая. На сопредельных территориях они встречаются в древностях таштыкской культуры [Вадецкая, 1999]. Сосуды на поддонах наиболее распространены на памятниках сайлапского этапа; реже фиксируются на горноелбанском и отсутствуют на новозыковском этапе, на которых встречены сосуды с намечающимся (исчезающим) поддоном.

Наиболее распространенной формой сосудов являются горшки с хорошо развитой шейкой и экватором выше центра тулова, с плоским дном. Основные пропорции - диаметр устья больше диаметра дна, а диаметр тулова может быть незначительно больше, равен высоте или незначительно меньше, чем высота сосуда.

На позднем этапе (новозыковском) встречаются горшки с прямым устьем и плоским дном, у которых диаметр устья больше диаметра дна, и горшки с неразвитой шейкой, шаровидным туловом (экватор примерно посередине тулова) и плоским дном с намечающимся поддоном, с диаметром устья большим, чем диаметр дна, диаметром тулова больше, чем диаметр устья, и высотой большей, чем диаметр тулова.

Кубковидные сосуды с приостренным дном в нашем регионе встречаются только на памятниках майминской культуры, как и пиалы с плоским дном, и сосуды на поддоне. 


\section{А.А. Казаков}

Самой распространенной фрормой венчика является прямая с округлым срезом. Достаточно характерны венчики прямые с горизонтальным срезом и подобные им, прямые с горизонтальным срезом и утолщением с внешней и внутренней стороны; профилированные с округлым срезом; прямые со срезом внутрь сосуда; профилированные с горизонтальным срезом; профилированные со срезом наружу. Остальные фрормы венчиков встречаются значительно реже. При большой вариативности форм венчиков к культуродиагностирующим этот признак вряд ли можно отнести.

Наряду с широким распространением гладкого штампа и редким использованием гребенчатого следует отметить высокую встречаемость на керамике майминской культуры полулунного штампа, который отмечен пока только на памятниках сайлапского этапа.

Это интересный орнаментальный элемент, который редко фриксируется в комплексах Алтайского края и распространен только на керамике майминской культуры с локализацией в междуречье Бии и Катуни и на посуде сошниковского этапа одинцовской культуры, что может свидетельствовать о большой доли майминского компонента в фрормировании этой культуры. Не случайно ареалы памятников майминской археологической культуры граничат с очагом фрормирования одинцовской культуры, памятниками сошниковского этапа. Полулунный штамп привнесен на одинцовскую керамику, вероятнее всего, от майминцев. Откуда он появился у них - вопрос открытый.

Наряду с гладким штампом на всех этапах повсеместно распространены ямки и пальцевые (ногтевые, защипные) орнаментальные элементы. Часто наблюдаются насечки и крупнозубый гребенчатый штамп. На памятниках сайлапского этапа встречен S-образный гладкий штамп (разновидность уточки). Фиксируются наколы неправильной формы, гладкий штамп с усиленным концом и широкий гладкий штамп с усиленным концом (горноелбанский и новозыковский этапы). Только на посуде одного памятника сайлапского этапа встречены каннелюры.

Следует отметить, что широко распространенные в предыдущий хронологический период жемчужины вообще не встречаются на майминской керамике, а отпечаток уголка лопаточки зафиксирован только в одном случае на одном памятнике, да и то с мешаным культурным слоем (быстрянско-майминским), и этот сосуд мог быть опубликован как майминский случайно.

Широкое распространение гладкого штампа является культуродиагоностирующим признаком майминской керамики, как уточка для кулайской.

Можно наметить эволюционные закономерности развития керамического комплекса майминской культуры.

Между майминской и предшествующей быстрянской керамикой существует крайне слабая связь; вероятнее всего, ее вообще нет. Об этом говорит отсутствие в комплексах майминской керамики широко распространенных в быстрянской культуре баночных фрорм, в орнаментации нет «жемчужника» и отпечатка уголка лопаточки, которые являются доминирующими орнаментальными элементами быстрянской посуды. Таким образом, в керамических комплексах майминской и быстрянской культур больше различий, чем сходства. Поэтому мы можем говорить о привнесении керамических традиций в ареал быстрянской культуры группой населения с иными культурными традициями, что очень похоже на ситуацию в лесостепном Алтае в первые века нашей эры, когда традиции населения раннего железного века были замещены традициями представителей фоминского этапа кулайской культуры [Грязнов, 1956, с. 99].

Достаточно узкая локализация сайлапской группы памятников в предгорной зоне Алтая и Присалаирья (правобережье р. Бии) (рис. 1) позволяет выделить территорию первоначального расселения мигрантов, которые затем распространились более широко, заняв и территории нижней Катуни и Горного Алтая. Несмотря на то что Майма 1 входит в эту группу памятников, по ряду признаков (отсутствие опубликованных сосудов на поддоне, таких орнаментальных элементов, как уточка и полулунный штамп) этот комплекс следует рассматривать как немного более поздний внутри этого этапа.

На сайлапском этапе характерными для керамики являются ранее неизвестные на этих территориях фрормы сосудов на поддоне, кубковидных сосудов, распространение ранее неизвестных орнаментальных элементов, таких как гладкий штамп, полулунный штамп и гладкая уточка.

Дальнейшее развитие этого комплекса происходило по пути смешения культурных традиций местного и пришлого населения - постепенного исчезновения поддонов, вытеснения полулунного штампа другими элементами орнамента, универсализации форм, что привело к фрормированию 
керамического комплекса новозыковского этапа, у которого очень много общего с керамическими комплексами одинцовской культуры (один из признаков универсализации - шаровидность тулова).

Затрудняясь с определением региона, из которого в ареал майминской культуры были привнесены инокультурные традиции в изготовлении керамики, можем предположить восточное направление культурных связей.

О значительной роли кулайского компонента в фрормировании майминской культуры говорит присутствие в керамическом комплексе на сайлапском этапе такого орнаментального элемента, как гладкая уточка. Справедливости ради, следует отметить и наличие сосудов на поддоне в керамическом комплексе новосибирского варианта кулайской кульутры [Троицкая, 1979, с. 97,108$]$. Вероятнее всего, эта морфологическая особенность была заимствована кулайскими племенами Новосибирского Приобья у культурного субстрата не майминской культуры, а более глобального культурно-исторического образования (метрополии), от которого и отпочковалось население, принесшее на берега Бии новые культурные традиции.

Расположение ареала памятников майминской культуры в зоне контактов двух крупнейших культурных суперрегионов - европейского и азиатского [Казаков, 2017a, 2017b] обусловило наличие и третьего компонента, а именно культур хуннуско-сяньбийско-жужанского круга, что выразилось в присутствии на территории распространения памятников майминской культуры погребально-поминальных комплексов булан-кобинской культуры, таких как Майма 7 [Серегин, Матренин, 2014, с. 119, 135], Усть-Муны 1 [Серегин, Матренин, 2014, с. 119, 142], Чултуков Лог 1 [Серегин, Матренин, 2014, с. 119, 245]. При наложении ареалов майминской и булан-кобинской археологических культур в районе нижнего течения Катуни неизбежно было взаимодействие - достаточно интенсивные контакты их носителей, что не могло не выразиться во взаимозаимствовании различных культурных традиций.

Ведущая роль в сложении булан-кобинской культуры восточного, хуннуского компонента [Серегин, Матренин, 2016, с. 145-147], являющегося базовым в формировании азиатского культурного суперрегиона [Казаков, 2017a, 2017b], объясняет наличие азиатского компонента в составе майминской культуры.

Таким образом, мы имеем дело с интересным культурным образованием, сформированным на основе культурных традиций, которые достаточно редко взаимодействуют друг с другом, расположенным в зоне контакта двух основных, крупнейших культурных суперрегонов Евразийского континента.

Кратко говоря об исторических судьбах майминской культуры, считаем наиболее вероятным ее трансформацию, ассимиляцию на основе очень плотного взаимовлияния с одинцовской культурой, в результате чего была сформирована новая археологическая культура - басандайская. Подобная гипотеза была высказана ранее [Казаков А.А., Казакова О.М., 2016; Григоров, Казаков, 2018], теперь же она получила еще одно подтверждение.

\section{БИБЛИОГРАФИЧЕСКИЙ СПИСОК}

Абдулаанеев М.Т. Раскопки у Маймы и Енисейского // Проблемы сохранения, использования и изучения памятников археологии. Горно-Алтайск, 1992. С. 52-53.

Абдулаанеев М.Т. Майминская культура: (Предварительные итоги и перспективы изучения) // Культурно-генетические процессы в Западной Сибири. Томск, 1993. С. 3-5.

Абдулганеев М.Т. Поселение Майма 1 и культурно-хронологическая атрибутация земледельческих поселений Горного Алтая // Древние поселения Алтая. Барнаул: АлтГУ, 1998. С. 165-171.

Абдулганеев М.T. Красногорский район в древности // Сохранение и изучение культурного наследия Алтая. Барнаул: АлтГУ, 2007. Вып. 16. С. 237-304.

Абдулганеев М.Т., Владимиров В.Н. Типология поселений Алтая 6-2 вв. до н.э. Барнаул: АлтГУ, 1997. $148 \mathrm{c}$.

Абдулганеев М.Т., Кунгурова Н.Ю., Пугачев Д.А., Скопинцева Г.В. Раскопки и разведки в северных предгорьях Алтая // Сохранение и изучение культурного наследия Алтайского края. Барнаул, 1995. Ч. 2. C. $129-133$.

Абдулганеев М.Т., Пугачев Д.А., Степанова Н.Ф. Исследования поселений эпохи железа у с. Карагуж на р. Иша (Северный Алтай) // Изучение историко-культурного наследия народов Южной Сибири. ГорноАлтайск: АКИН, 2005. Вып. 2. С. 51-64.

Абдулганеев М.Т., Степанова Н.Ф., Служак И.В., и др. Раскопки аварийных памятников на р. Иша // Сохранение и изучение культурного наследия Алтайского края. Барнаул: Азбука, 2001. С. 93-97. 


\title{
А.А. Казаков
}

Вадецкая Э.Б. Таштыкская эпоха в древней истории Сибири. СПб.: Петерб. Востоковедение, 1999. $440 \mathrm{c}$.

Григоров Е.В., Казаков А.А. Барнаульско-Бийское Приобье в 1-12 вв. (по данным погребального обряда). Барнаул: АлтГУ, 2018. 230 с.

Грязнов М.П. История древних племен Верхней Оби по раскопкам близ с. Большая Речка // МИА. 1956. № 48. 256 c.

Казаков А.А. Поселение Сайлапский Взвоз // Проблемы охраны, изучения и использования культурного наследия Алтая. Барнаул: АлтГУ, 1995. С. 150-153.

Казаков А.А. Одинцовская культура Барнаульско-Бийского Приобья. Барнаул: БЮИ МВД России, 2014. $152 \mathrm{c}$.

Казаков А.А. Европа и Азия как самостоятельные мультикультурные провинции // Учен. записки (Алтайская государственная академия культуры и искусств). Культура евразийского региона: Материалы I Междунар. науч.-практ. форума, г. Барнаул, 24-27 мая 2017 г. Барнаул: Изд-во АГИК, 2017а. № 2 (12). C. $10-13$.

Казаков А.А. Ментально-культурные суперрегионы в эпоху Великого переселения народов // V (XXI) Bсеpoc. археол. съезд [Электрон. ресурс]. Электрон. текст. данные (36,739 Мб). Барнаул: АлтГУ, 2017b. С. 439440.

Казаков А.А., Демин М.А. Аварийные работы в Красногорском районе // Проблемы сохранение, использования и изучения памятников археологии. Горно-Алтайск, 1992. С. 70-71.

Казаков А.А., Казакова О.М. О центрах культурогенеза на юге Западной Сибири в первом тысячелетии // Известия АлтГУ: (Ист. науки и археология). 2016. № 4 (92). С. 238-243.

Кунгуров А.Л., Горбунов В.В. Средневековое поселение Ушлеп 5 // Культура древних народов Южной Сибири. Барнаул, 1993. С. 77-80.

Матренин С.С., Тишкин А.А. Опыт выделения локально-территориальных групп населения Алтая хуннуского времени (по материалам погребальных памятников) // Теория и практика археологических исследований. Барнаул: АлтГУ, 2007. С. 102-115.

Серегин Н.Н., Матренин С.С. Археологические комплексы Алтая 2 в. до н.э. - 9 в. н.э.: История исследований и основные аспекты интерпретации. Барнаул: Азбука, 2014. 230 с.

Серегин Н.Н., Матренин С.С. Погребальный обряд кочевников Алтая во 2 в. до н.э. -9 в н.э. Барнаул: АлтГУ, 2016. 272 с.

Скопинцева Г.В. Новые памятники первой половины 1 тыс. н.э. в предгорьях Алтая // Культура древних народов Южной Сибири. Барнаул, 1993. С. 62-71.

Соенов В.И., Соенов Д.В., Константинов Н.А. Древние городища Алтая. Горно-Алтайск: ГАГУ, 2016. 244 с.

Троицкая Т.Н. Кулайская культура в Новосибирском Приобье. Новосибирск: Наука, 1979. 128 с.

Чиндина Л.А. Древняя история Среднего Приобья в эпоху железа. Томск: ТГУ, 1984. 256 с.

Чиндина Л.А. История Среднего Приобья в эпоху раннего средневековья: (Релкинская культура). Томск: ТГУ, 1991. $184 \mathrm{c.}$

\author{
A.A. Kazakov \\ Barnaul Law Institute of the Ministry of Internal Affairs of Russia \\ Chkalova st., 49, Barnaul, 656038, Russian Federation \\ E-mail: kaa-2862@mail.ru
}

\section{THE CERAMIC COMPLEX OF THE MAYMA ARCHAEOLOGICAL CULTURE}

The Mayma archaeological culture was designated more than 25 years ago; however, no attempts have been undertaken since then to scrutinize this important cultural and chronological entity. Despite the accumulation of a large amount of ceramic complex material, which is known to be the most representative source, the vast majority of this material is yet to be analysed. In this work, the author investigates published data on ceramic complexes found at the Mayma archaeological culture site using standard qualitative and quantitative analytical methods. The conclusions obtained by qualitative analysis according to 5 parameters (shape of vessel, shape of bottom, shape of neck, any ornamental element, ornamental composition) were additionally tested by cluster analysis. Three groups of complexes, corresponding to the 3 developmental stages of the Mayma archaeological culture, were identified as Sailap, Gornoelban and Novozykovo on the basis of a correlation of the qualitative and quantitative data. Available dating information allowed the author to develop a relative chronology of the stages. It is shown that the earliest was Sailap, then Gornoelban, and finally Novozykovo. Absolute dating for the 3 stages is proposed as follows: Sailap - 1st century B.C. - 4th century A.D.; Gornoelban - 4th-6th centuries A.D.; Novozykovo - 6th-8th centuries A.D. A comparison of the characteristics of the ceramic complexes at the different stages revealed several distinct evolutionary patterns. A comparison of the ceramic complex from the preceding period found in this region (Bystryanka archaeological culture) with the Mayma culture revealed no common features. This allowed a conclusion to be drawn that the population migrated to the territory of the middle section of the Biya river (where the complexes of the earliest Sailap stage are located) and subsequently spread over the 


\section{Керамический комплекс майминской археологической культуры}

entire region of the Mayma archaeological culture. A hypothesis is advanced concerning the later transformation of the Mayma archaeological culture as a result of its merger with the Odintsovo culture as evidenced in the artifacts of the Basandaika archaeological culture.

Key words: ceramics, morphology, ornament, archaeological culture, stage, evolution, analysis.

DOI: 10.20874/2071-0437-2018-43-4-074-083

\section{REFERENCES}

Abdulganeev M.T. (1992). Excavations at Maima and Yenisei. Problemy sokhraneniia, ispol'zovaniia $i$ izucheniia pamiatnikov arkheologii, Gorno-Altaisk, 52-53.

Abdulganeev M.T. (1993). Maima culture: (Preliminary results and prospects of studying). Kul'turnogeneticheskie protsessy v Zapadnoi Sibiri, Tomsk, 3-5.

Abdulganeev M.T. (1998). The settlement of Maima 1 and cultural-chronological attributing of agricultural settlements of Mountain Altai. Drevnie poseleniia Altaia, Barnaul, 165-171.

Abdulganeev M.T. (2007). Krasnogorsk district in ancient time. Sokhranenie i izuchenie kulturnogo naslediia Altaia, 16, Barnaul, 237-304.

Abdulganeev M.T., Vladimirov V.N. (1997). Typology of settlements of Altai in 6-2 centuries B.C., Barnaul.

Abdulganeev M.T., Kungurova N.Y., Pugachev D.A., Skopintseva G.V. (1995). Exploration in the foothills of Altai. Sokhranenie i izuchenie kul'turnogo naslediia Altaiskogo kraia, 2, Barnaul, 129-163.

Abdulganeev M.T., Pugachev D.A., Stepanova N.F. (2005). Studying Iron Age settlements near Karaguzh village at the Isha river (Northern Altai). Izuchenie istoriko-kul'turnogo naslediia narodov luzhnoi Sibiri, (2), GornoAltaysk, 51-64.

Abdulganeev M.T., Stepanova N.F., Sluzhak I.V., Chekryzhova O.I. (2001). Emergency excavations of monuments on the river Isha. Sokhranenie $i$ izuchenie kul'turnogo naslediia Altaiskogo kraia, Barnaul, 93-97.

Chindina L.A. (1984). Ancient history of the Middle Ob region in the Iron Age, Tomsk.

Chindina L.A. (1991). History of the Middle Ob Area in the Early Middle Ages: (Relka culture), Tomsk.

Griaznov M.P. (1956). History of ancient tribes of the Upper Ob according to excavations near the village of Bolshaya Rechka. Materialy I issledovania po arkheologii SSSR, (48).

Grigorov E.V., Kazakov A.A. (1997). The Barnaul-Biysk Ob Region in the 1st-12th centuries A.D. (according to funeral ritual), Barnaulю

Kazakov A.A. (1995). Settlement Sailapski Vzvoz. Problemy okhrany, izucheniia i ispol'zovaniia kul'turnogo naslediia Altaia, Barnaul, 129-163.

Kazakov A.A. (2014). Odintsovo culture of the Barnaul-Biysk Ob Area, Barnaul.

Kazakov A.A. (2017a). Europe and Asia as independent multicultural provinces. Uchenye zapiski (Altaiskaia gosudarstvennaia akademiia kul'tury $i$ iskusstv). Kul'tura evraziiskogo regiona: Materialy I Mezhdunar. nauch.prakt. foruma, g. Barnaul, 24-27 maia 2017 g., (2), Barnaul, 10-13.

Kazakov A.A. (2017b). Mental and cultural superregions in the Epoch of the Great Migration of the Peoples. V (XXI) Vserossiiskii arkheologicheskii s"ezd [Elektronnyi resurs], Barnaul, 439-440.

Kazakov A.A., Demin M.A. (1992). Excavations at Maima and Yenisei. Problemy sokhranenie, ispol'zovaniia i izucheniia pamiatnikov arkheologii, Gorno-Altaisk, 129-163.

Kazakov A.A., Kazakova O.M. (2016). On cultural genesis in the South of Western Siberia in first millenium. Izvestiia AltGU. Istoricheskie nauki i arkheologia, (4), Barnaul, 129-163.

Kungurov A.L., Gorbunov V.V. (1993). The medieval village of Ushlep 5. Kul'tura drevnikh narodov luzhnoi Sibiri, Barnaul, 77-80.

Matrenin S.S., Tishkin A.A. (2007). Experience in identification of local territorial groups of Altai in Hunnic time (according to materials of burial monuments). Teoriia i praktika arkheologicheskikh issledovanii, 16, Barnaul, 237-304.

Seregin N.N., Matrenin S.S. (2014). Archaeological complexes of Altai in the 2nd century B.C. - 9th century A.D.: History of research and key aspects of interpretation, Barnaul. Barnaul.

Seregin N.N., Matrenin S.S. (2016). Burial ritual of Altai nomads in the 2nd century B.C. - 9th century A.D.,

Skopintseva G.V. (1993). New monuments of the first half of 1st millennium A.D. in the foothills of Altai. Kul'tura drevnikh narodov luzhnoi Sibiri, Barnaul, 62-71.

Soenov V.I., Soenov D.V., Konstantinov N.A. (2016). Ancient settlements of Altai, Gorno-Altaysk.

Troitskaia T.N. (1979). Kulaika culture in the Novosibirsk Ob region, Novosibirsk.

Vadetskaia E.B. (1999). Tashtyk epoch in ancient history of Siberia, St. Petersburg. 